\title{
COMUNICAÇÃO EMPÁTICA NO ENSINO A DISTÂNCIA: ANÁLISE DAS INTERAÇÕES TUTOR-DISCENTE
}

\author{
EMPATHIC COMMUNICATION IN E-LEARNING: \\ ANALYSIS OF TUTOR-STUDENT INTERACTIONS
}

\section{COMUNICACIÓN EMPÁTICA EN EL APRENDIZAJE ELECTRÓNICO: ANÁLISIS DE LAS INTERACCIONES} TUTOR-ESTUDIANTES

\author{
Julio Cesar Teixeira de Freitas ${ }^{1}$ \\ TAmara de Souza CAMPos ${ }^{2}$ \\ Elisa Maria dos AnJos ${ }^{3}$ \\ ${ }^{1}$ Colégio Pedro II (CPII), Rio de Janeiro/RJ - Brasil \\ ${ }^{2}$ Universidade Estácio de Sá (UNESA), Petrópolis/RJ Brasil \\ ${ }^{3}$ Universidade Federal do Maranhão (UFMA), \\ São Luís/MA - Brasil
}

Resumo O objetivo deste estudo é avaliar as interações ao longo de um semestre entre alunos de uma disciplina do Ensino Superior gratuito em Pedagogia de um consórcio público de universidades brasileiras e a equipe de tutoria. Tendo como objetivo principal a análise da presença ou não da empatia entre os interlocutores em questão, utilizamos a metodologia tanto quantitativa quanto qualitativa. A partir da análise do corpus, as mensagens oriundas da "Sala de Tutoria", buscamos averiguar os temas mais recorrentes, bem como, a presença da comunicação empática nas interações. Com relação aos temas, 86,9\% giravam em torno de notas. Isso demonstra um excesso de preocupação com a avaliação, ainda mais se compararmos com interações cujo objetivo era discutir algum conteúdo das aulas - índice que representou apenas $1,4 \%$ das conversas. Quanto à natureza empática da comunicação, percebemos algum traço empático em $52,2 \%$. Desse conjunto, $92,5 \%$ das conversas foram classificadas como oportunidades empáticas negativas, nas quais os alunos demonstravam algum sentimento negativo. Quando analisamos as respostas oferecidas pelos tutores, cerca de $67 \%$ são classificadas como terminadores empáticos e somente $15,3 \%$ das respostas 
foram percebidas como apropriadas, no sentido de oferecer um retorno às demandas emocionais demonstradas pelos alunos.

Palavras-chave: Educação a distância; Empatia; Comunicação empática.

Abstract The purpose of this study is to evaluate the interactions over a semester between students of a Higher Education discipline in Pedagogy of a public consortium of Brazilian universities and the mentoring team. Having as main objective the analysis of the presence, or not, of the empathy between the interlocutors in question, we use both quantitative and qualitative methodology. From the analysis of the corpus, the messages from the "Tutoring Room", we sought to find out the most recurrent themes, as well as the presence of empathic communication in the interactions. Regarding the themes, $86.9 \%$ revolved around notes. This shows an excess of concern with the evaluation, more significant when we compare with interactions whose objective was to discuss some content of the classes - an index that represented only $1.4 \%$ of the conversations. As for the empathic nature of communication, we found some empathic trait in $52.2 \%$. Of this group, $92.5 \%$ of the conversations were classified as negative empathic opportunities, in which the students showed some negative feelings. When we analyze the responses offered by the tutors, about $67 \%$ are classified as empathic terminators and only $15.3 \%$ of the answers were perceived as appropriate, in order to offer a return to the emotional demands demonstrated by the students.

KeYWORDS: E-LEARNING; EMPATHY; EMPATHIC COMMUNICATION.

Resumen El objetivo de este estudio es evaluar las interacciones en un semestre entre alumnos de una disciplina de la Enseñanza Superior gratuita en Pedagogía de un consorcio público de universidades brasileñas y el equipo de tutoría. Teniendo como objetivo principal el análisis de la presencia o no de la empatía entre los interlocutores, utilizamos de metodología tanto cuantitativa como cualitativa. A partir del análisis del corpus, los mensajes oriundos de la "Sala de Tutoría", buscamos averiguar los temas más recurrentes, así como la presencia de la comunicación empática en las interacciones. Con respecto a los temas, el $86,9 \%$ giraba en torno a notas. Esto demuestra un exceso de preocupación con la evaluación, aún más de comparar con interacciones cuyo objetivo era discutir algún contenido de las clases - índice que representó apenas el 1,4\%. En cuanto a la naturaleza empática de la comunicación, percibimos algún rasgo empático en el 52,2\%. De ese conjunto, el 92,5\% de las conversaciones fueron clasificadas como oportunidades empáticas negativas, en las cuales los alumnos demostraban algún sentimiento negativo. Al analizamos las respuestas ofrecidas por los tutores, cerca del $67 \%$ son clasificadas como terminadores empáticos y sólo el 15,3\% de las respuestas fueron percibidas como apropiadas, en el sentido de ofrecer un retorno a las demandas emocionales demostradas por los alumnos.

Palabras clave: Enseñanza Electrónica; Empatia; Comunicación Empática. 


\section{INTRODUÇÃO}

Um dos teóricos mais conhecidos da Comunicação Social, Marshall McLuhan, adiantou em pelo menos duas décadas ${ }^{1}$ a cultura tecnológica que hoje experimentamos. O filósofo afirmava em plena década de 60 , com um mundo esfacelado em dois polos em decorrência da Guerra Fria, que todos os indivíduos do planeta ficariam interligados a partir dos meios de comunicação, formando uma "aldeia global" (1977).

Foi essencialmente no século XX que os meios de comunicação de massa foram largamente consumidos pela população. Com a invenção do cinematógrafo em 1895 , o rádio em 1920 e a TV, a partir de 1940, o modo de ser e estar no mundo foi alterado radicalmente. Se antes as instituições mais tradicionais como a família e a igreja eram as grandes responsáveis pela educação dos indivíduos, os meios de comunicação conquistaram espaço expressivo no que diz respeito a ancorar o sujeito no mundo.

Ao longo do século, os meios de comunicação massivos viviam sob a égide do paradigma um-para-todos, pois existiam poucos centros emissores de produção e difusão de conteúdo (um), que levavam essas informações para a grande massa (todos). Não cabia retorno da população com relação ao conteúdo veiculado, pois se tratava de uma relação unidirecional, verticalizada, com pouca oferta de informação e quase sem espaço para contestação das produções.

Não é à toa que, nesse ínterim, aparecem as primeiras teorias da comunicação que concebem a massa como acrítica, amorfa, e sem capacidade de resistência perante os conglomerados de comunicação. Nessa percepção acerca do que era comunicar, o entendimento do receptor, suas sensações e sentimentos eram irrelevantes e nem mesmo consideradas uma questão, tanto que os famosos estudos de recepção só ganham fôlego a partir da década de 80 .

Fazendo uma analogia com a educação, durante muito tempo foi defendido o modelo de educação bancária (FREIRE, 1981), em que o aluno (do latim, "sem luz"), recebia as informações do único produtor e difusor de conhecimento: o professor. O aluno quase não tinha espaço para se manifestar, salvo quando autorizado pelo professor.

Os jornais e revistas também tinham, de certa forma, o monopólio da fala. Os veículos decidiam publicar ou não alguma carta de leitor, ou mesmo num programa televisivo ou radiofônico, em que o espectador só podia aparecer e ter voz se assim o fosse permitido.

Na sala de aula a dinâmica é similar. Se antes cabia uma atitude passiva durante as aulas, agora o aluno possui outro processo cognitivo. Ele já cresceu sendo um prosumer, ${ }^{2}$ termo da língua inglesa que une os vocábulos "producer" e "consumer". Obviamente, para o aluno, acostumado a ser um sujeito ativo, que posta, curte, comenta e compartilha, a ideia de escutar o tempo todo, numa postura mais passiva, é uma proposta, no geral, desinteres-

\footnotetext{
1 Duas décadas se levarmos em consideração a criação da ARPANET, pelo Departamento de Defesa dos EUA, em 1969. Mas se o mundo globalizado e interconectado é um dos fenômenos mais típicos de meados da década de 90.

2 Toffler (1980).
} 
sante. Recorremos novamente a McLuhan (1996), que dizia que as sociedades sempre foram moldadas mais pela natureza dos meios que os homens usam para se comunicar do que pelo conteúdo da comunicação propriamente. Ou seja, estava no centro das preocupações do canadense a ideia de que as características de cada meio de comunicação eram responsáveis por gerar sensações específicas, relacionadas à natureza do meio que é consumido.

A postura dos cidadãos no que tange ao consumo de informações mudou e analisar as formas de interação entre receptores e meios de comunicação nos ajuda a entender a mudança de perfil do indivíduo hodierno e, por extensão, do próprio aluno. Se antes, o público apenas recebia as informações, notícias e produtos midiáticos, agora, ele também atua como um co-construtor dos mesmos. Tal fenômeno, logicamente, gera reflexos para a dinâmica da sala de aula, exigindo dos professores um repensar da prática didática, de modo a engajar o aluno na construção do conhecimento.

Frente à profunda mudança no processo de comunicação com o crescimento da internet, e seus efeitos nas comunicações ocorridas no ambiente do e-learning, entender como a prática dessa comunicação ocorre e sua adequação ao desenvolvimento de um ambiente receptivo aos alunos e capaz de aprofundar a construção do conhecimento torna-se de vital importância.

A tendência do aluno parece a de resistir cada vez mais a uma aula meramente expositiva, em que só o professor detenha o turno de fala. Nesse sentido, o EAD parece uma metodologia atual, com o estudante operando mais como um sujeito ativo do seu conhecimento, tendo na figura do tutor um mediador que o auxilia na construção do conhecimento.

Num primeiro momento, conceituamos a empatia e a sua utilização on-line, definindo a comunicação empática e sua relevância no processo de aprendizagem. Sobre essas definições, desenvolvemos um novo conceito de comunicação empática e um sistema de avaliação das interações, mais adequados ao ambiente educacional a distância.

Em seguida, apresentamos e analisamos um estudo de caso das interações estabelecidas entre equipe de tutoria e alunos de uma disciplina oferecida para a Pedagogia, ao longo de um semestre. O curso de graduação em questão pertencia a uma universidade pública. Objetivamos verificar em que medida as interações tutor EAD e discentes podem ser classificadas como comunicação empática e as consequências da utilização dos diferentes tipos de comunicação na construção do ambiente de aprendizagem. Este estudo apresenta-se como um trabalho interdisciplinar, mobilizando os campos da Comunicação, Educação, Psicologia e Sociolinguística.

\section{Perspectivas de empatia}

Quando falamos em interações sociais, a empatia parece parte essencial, sendo ainda mais importantes em processos de aprendizagem. Por ser um construto multidimensional, oferece a oportunidade para que diferentes linhas de investigação desenvolvam suas próprias abordagens, nem sempre coincidentes. Assim, podemos distinguir as seguintes perspectivas sobre o conceito de empatia: a) emocional, b) cognitiva, c) situacional e d) comportamental. 
A perspectiva emocional é ancorada na definição de Lipps, que utilizou o termo Einfülung como uma forma de desenvolver no Eu um sentimento semelhante ao do outro. A empatia seria o sentimento vicário que permite a compreensão imediata do sentimento do outro. Alguns autores acreditam que esse sentir seja originado por um processo natural do ser humano de imitação interna, sendo essa também a origem do que chamamos de contágio emocional (SALGADO, 2000).

A partir dos anos 1930, essa abordagem deu lugar a uma visão mais cognitiva. Dentro dessa perspectiva, Mead (1934 apud HOGAN, 1969) defende que considerar a perspectiva do outro auxilia no entendimento de seus sentimentos. Dymond (1949) cunha o termo "role-taking", adoção de perspectiva, definindo empatia como "a transposição imaginativa de alguém para dentro do pensamento, sentimento e ação do outro, de forma a estruturar o mundo como o outro o vê" (p. 127). A perspectiva cognitiva foi dominante entre os estudiosos até os anos 1960 .

As duas perspectivas apresentadas são, até o atual momento, amplamente utilizadas e, desde a década de 1960, a integração entre essas duas vertentes tem sido objeto de desenvolvimento. Davis (1980, p. 3) defende que as duas abordagens fazem parte de um mesmo "sistema interdependente no qual cada parte influencia a outra, e que nunca será totalmente entendido no caso dos esforços serem concentrados em um único aspecto". Esse mesmo autor, em 1983, desenvolve um modelo integrado de empatia constituído de quatro fases: a) a adoção de perspectiva; b) a fantasia, que reflete uma tendência pessoal em transportar-se para os sentimentos de personagens fictícios; c) a preocupação empática; e d) a angústia pessoal. Nesse modelo, é perceptível a presença tanto da perspectiva cognitiva, itens (a) e (b), como a perspectiva afetiva, itens (c) e (d).

De Waal (2008) divide o processo empático em três níveis, oferecendo uma clara visão de como os processos emocionais e cognitivos da empatia operam em conjunto. Segundo essa sistematização, o processo empático incluiria a) contágio emocional, b) preocupação solidária e c) adoção de perspectiva empática. O contágio emocional é uma "resposta emocional pela manifestação de emoções por outros" (p. 283) e representa a manifestação mais afetiva do processo empático. A preocupação solidária vai um passo além do contágio emocional, apresentando um aspecto cognitivo de "avaliação da situação do outro e uma tentativa de entender as causas das emoções do outro" (p. 283). O último estágio seria a adoção de perspectiva empática, onde há uma combinação entre a adoção do ponto de vista do outro e um engajamento emocional.

Enquanto essas duas vertentes entendem a empatia como uma habilidade intrínseca do ser humano, uma visão situacional pensa o processo empático como resultado da interação entre variáveis pessoais (capacidades biológicas e vivências de aprendizagem) e variáveis situacionais (força da situação e similaridade da pessoa com quem se vai empatizar) (DAVIS, 1996).

A visão situacional considera que, apesar do processo empático ocorrer de forma automática, seriam necessárias algumas condições mínimas, como a atenção do observador para a situação emocional do outro e alguma experiência passada do observador relacionada ao estado ou situação do outro (WONDRA \& ELLSWORTH, 2015). 
A última perspectiva apresentada, a comportamental, percebe a empatia não somente como um processo de gerar um sentimento semelhante ou uma compreensão do sentimento do outro, mas inclui a necessidade de uma resposta apropriada por parte do Eu. Essa visão incorpora a temática da compaixão como uma atitude necessária a fim de complementar o processo empático.

O trabalho de Marshall et al. (1995) assume essa perspectiva ao elaborar o conceito de processo empático, com foco na agressão sexual, contendo quatro etapas: a) reconhecimento emocional, b) adoção de perspectiva, c) replicação emocional e d) decisão de resposta. Dessa forma, a decisão de resposta envolve uma escolha quanto ao comportamento a ser seguido frente aos sentimentos despertados.

Apesar de apresentar uma extensão do conceito inicial, uma vez que a empatia, por definição, significa estar dentro da experiência de alguém, sem incluir avaliações dos comportamentos subsequentes, essa abordagem é especificamente útil quando consideramos o processo de comunicação. Esse processo exige, por sua natureza, o feedback. Dessa forma, como nosso trabalho tem por objeto o processo de comunicação tutor-discente, utilizaremos essa abordagem como paradigma de avaliação.

\section{EMPATIA ON-LiNe}

Com o crescimento da internet e de todas as aplicações interativas localizadas nesse meio (redes sociais, e-commerce, e-learning etc.), a discussão sobre a empatia voltou-se também para o universo web. Uma vez que grande parte da comunicação on-line é realizada de forma textual e a empatia tem suas bases associadas, principalmente, à percepção de sinais não verbais, como a postura, voz, olhar (EISENBERG \& FABES, 1989), fica a dúvida sobre como o processo empático pode ocorrer no ambiente digital.

Preece \& Ghozati (2001) destacam que, em um ambiente textual assíncrono, a escolha das palavras, frases e a estrutura das sentenças constituem a principal maneira de comunicar as emoções. Além das palavras, sinais específicos utilizados também são relevantes, como o emprego de emoticons, espaços, letras maiúsculas, caracteres especiais do American Standard Code for Information Interchange (ASCII) ou a pontuação diferenciada (sinal de exclamação ou interrogação duplos etc.). Tal ambiente descrito pelos autores já mencionados corresponde à realidade de nosso corpus, já que a sala de tutoria analisada também envolve uma comunicação assíncrona, com trocas de mensagens textuais entre discentes e tutores no Fórum da Sala de Tutoria. Eventualmente algum elemento não verbal é acionado, como os emoticons.

Dessa forma, apesar das limitações apresentadas por aplicações na internet com formatos mais textuais, existem maneiras de desenvolver a empatia, percebendo as dicas que são enviadas por meio dos elementos supracitados. A análise desses elementos possibilita, em muitos casos, a compreensão das emoções envolvidas na interação e no desenvolvimento da empatia de base cognitiva.

Nesse momento, cabe definirmos a noção de e-learning e tutoria nas quais baseamos o presente trabalho. Segundo Paiva et al. (2004, p. 5), o e-learning "é caracterizado 
pela separação física entre o professor e o aluno e por um objetivo comum: disponibilizar um conjunto de recursos e técnicas a pessoas que desejem estudar em regime de auto-aprendizagem". Os autores defendem também que, ao nos referirmos à educação, não se pode pensar somente na transmissão de informação, sendo fundamental considerarmos "o desenvolvimento harmonioso do ser humano nos seus vários aspectos, intelectuais, morais e físicos, bem como a sua inserção na sociedade" (p. 6). Assim, a visão dos autores corrobora com a importância de termos um ambiente empático mesmo quando utilizamos as tecnologias digitais como meio.

Machado e Machado (2004) diferenciam a tradicional visão de tutoria, onde "o tutor dirigia, orientava, apoiava a aprendizagem dos alunos, mas não ensinava" (p. 2), sendo o ensino realizado pelos materiais disponibilizados. Atualmente, o papel do tutor e o do professor se misturam, sendo ele responsável por promover uma compreensão profunda do conteúdo disponibilizado. Bernardino (2011) considera o tutor protagonista da ação educativa, sendo responsável pela construção coletiva do conhecimento. Para tanto, deve garantir a "qualidade comunicacional" (p. 3) por meio de uma "conversação didática e criativa" (p. 3), fomentando o pensamento dos alunos. O autor também destaca, entre os atributos psicológicos e éticos que um tutor deve possuir, a necessidade da empatia com os alunos.

Considerando esse ambiente, de ensino a distância, a empatia permite a construção e manutenção de relacionamentos de ensino-aprendizagem (WALSHAWA \& DUNCANB, 2015), possibilitando "ao professor e aos estudantes interpretarem-se mutuamente durante o engajamento dialógico" (p. 306) também nas interações on-line, mesmo que a experiência seja potencialmente diferente.

Para Kehrwald (2008), esse fato se relaciona com o desenvolvimento de um senso de presença facilitado pelas relações empáticas. O senso de presença cria uma "ilusão de realidade na percepção de participantes de situações mediadas" (p. 91). Essa percepção do outro como uma pessoa real e presente está intimamente ligada ao reconhecimento das similaridades com os demais participantes. A percepção de presença advém da combinação de “a) mensagens online dos participantes e b) o modo como essas mensagens são interpretadas pelos demais" (p. 95).

A interpretação das mensagens se destaca como fator fundamental de construção do entendimento e conhecimento que permite a "criação de um ambiente não ameaçador e acolhedor" (WALSHAWA \& DUNCANB, 2015, p. 305). Logo, o processo de comunicação empática torna possível a interpretação do outro e a modulação da linguagem utilizada, facilitando o desenvolvimento de uma comunidade efetiva de aprendizagem o que, certamente, é um dos maiores desafios de qualquer iniciativa de e-learning.

$\mathrm{O}$ desenvolvimento do engajamento empático em um ambiente de ensino-aprendizagem on-line é resultado de um processo dialógico, ancorado na interação continuada entre tutores e alunos. A análise e entendimento do processo de comunicação que conduz a esse engajamento torna-se essencial a fim de criar ambientes mais efetivos em seus propósitos de aprendizagem.

Para Vedove e Camargo (2008, p. 161), a "empatia faz parte das competências pessoais e de trabalho colaborativo em equipe que o tutor deve apresentar para desenvolver um 
bom trabalho com os alunos". Segundo os autores, essa capacidade permitirá que os tutores entendam as atitudes dos alunos e reajam "de forma mais adequada" (p. 161).

A mudança na atitude do tutor, adequando sua reação perante o aluno, permite o estreitamento dos laços afetivos, ajudando o aluno com suas emoções, amparando e conduzindo a fim de facilitar sua aprendizagem (WALSHAW e DUNCAN, 2015).

\section{CoMunicaÇão EMPÁtica}

Embora não haja uma origem clara do termo comunicação empática, sua essência considera a transmissão dos sentimentos vivenciados por uma ou pelas partes envolvidas na interação. Rogers (1957), ao desenvolver seu modelo de terapia centrada no paciente, coloca como uma condição necessária para que a mudança ocorra, o entendimento empático do paciente. Esse entendimento é construído tendo por base o diálogo empático e a observação.

Aliás, a área da saúde se destaca por desenvolver os modelos de processo de comunicação empática mais significativos para a aplicação prática. Entre eles, Platt \& Keller (1994) apresentam um modelo de seis passos que utilizam a fim de desenvolver a capacidade de entendimento e comunicação empática em médicos. As etapas do processo, segundo os autores, são: 1) ter consciência do momento afetivo; 2) parar para refletir; 3) dar nome aos sentimentos; 4) apreciar o sentimento; 5) aceitar as ações passadas do paciente; e 6) oferecer ajuda para momentos futuros. Dessa forma, para os autores, a comunicação empática é uma habilidade cognitiva, que pressupõe o entendimento dos sentimentos do paciente.

Suchman et al. (1997) possuem um entendimento semelhante quanto à comunicação empática, que teria dois componentes básicos, um cognitivo, que seria o correto entendimento da emoção que o interlocutor manifesta e, outro, comportamental, que reside em uma resposta face a um sentimento demonstrado por outrem. Os autores diferenciam momentos que devem ser avaliados dentro do processo de comunicação a fim de construir uma interação empática. Desses momentos destacamos a) a oportunidade empática, na qual o interlocutor manifesta de maneira explícita uma emoção, b) a resposta empática, onde o interlocutor reconhece e comunica ao outro que entendeu a emoção em voga e c) o terminador empático, onde o interlocutor direciona a conversa para longe da emoção demonstrada pelo outro.

Os autores realizaram a análise de 11 transcrições e sete videotapes de consultórios de cuidado primário. Cada membro do grupo de pesquisa analisou as transcrições, avaliando o caráter empático contido nelas. Após essa etapa, os membros se reuniram a fim de comparar e discutir sobre as avaliações dadas, com o intuito de chegar a um consenso. Como resultado de sua pesquisa, Suchman et al. (1997) desenvolveram uma definição dos termos a fim de classificar cada trecho das transcrições das interações, conforme segue: i) oportunidade empática, ii) resposta empática, iii) terminador de oportunidade empática, iv) oportunidade empática perdida, v) oportunidade empática potencial, vi) continuador de oportunidade empática potencial, vii) terminador de oportunidade empática potencial.

Em contrapartida à produção relevante sobre o tema na área de saúde, são raros os trabalhos científicos de Educação que abordem o tema. Dentro desse pequeno grupo de 
pesquisas, não há referência a uma definição de comunicação empática no ambiente educacional nem sistemas desenvolvidos a fim de avaliar as comunicações entre professores/ tutores e estudantes, embora autores reconheçam a relevância desse tipo de comunicação nesse ambiente. Essa lacuna conceitual acaba por tornar a presente pesquisa ainda mais relevante em suas propostas e conclusões.

Um dos trabalhos que enfatizam o meio educacional é o de Vedove \& Camargo (2008), que destaca a comunicação empática como fundamental no desenvolvimento da empatia por parte do tutor. Assim, o tutor deveria possuir a capacidade de detectar "pistas emocionais" nos alunos, "entendendo o que o outro está dizendo e sentindo" (p. 161). Da mesma forma, o tutor deveria ter a capacidade de demonstrar apoio, oferecendo sugestões e feedback ao aluno de forma a construir um relacionamento ancorado na confiança e em uma "sintonia afetiva" (SOUZA, 2004 apud VEDOVE \& CAMARGO, 2008, p. 162).

Como forma de sistematizar nosso estudo, tornou-se necessário desenvolver uma conceituação para o termo comunicação empática que servisse de base para o detalhamento dos códigos a serem analisados nas interações que formam o corpus da pesquisa. Com esse intuito, definimos comunicação empática como aquela que permite o entendimento das emoções e sentimentos que estão sendo vivenciados por uma ou ambas as partes, ou que busca criar condições para o desenvolvimento de uma relação de confiança para que haja um maior entendimento das emoções e sentimentos em jogo.

Cabe ressaltar que a comunicação empática só pode ser inferida a partir da análise de cada interação, tendo em vista que nossa abordagem se ancora no Interacionismo Simbólico. A escola do interacionismo simbólico abarca estudos com uma linha sociológica e sociopsicológica, tendo como enfoque os processos de interação, ressaltando que a natureza da interação entre seres humanos envolve a interpretação. "Interpretar as ações dos outros é apontar para si mesmo que a ação tem este ou aquele sentido, esta ou aquela natureza" (BLUMER, 2013, p. 77). Quando interagimos, não reagimos mecanicamente, e sim inferimos sentido a partir do outro e do contexto.

O processo comunicacional, portanto, envolve uma série de alinhamentos (GOFFMAN, 2002), que são os posicionamentos que adotamos face àquilo que interpretamos de nosso interlocutor. Nesse sentido, uma interação é muito dinâmica e pode ter um momento mais hostil, seguido por uma comunicação empática, por exemplo. Portanto, nosso esforço girará em torno de categorizarmos o momento em que ocorre a comunicação empática, mesmo que esse momento seja apenas um microenquadre de uma interação.

O contexto é um dos componentes fundamentais nesse processo de interpretação e diversos elementos o compõem. Podemos definir contexto como "ambientes dinâmicos, interacionalmente construídos, que podem mudar a cada momento" (RIBEIRO \& PEREIRA, 2002). O contexto engloba as características do ambiente físico, virtual e/ou institucional que servem de cenário para o encontro, bem como, o conteúdo do discurso e a maneira como é empregado, o tópico em discussão na interação. Todos esses elementos influenciam a ação em curso. É similar a um jogo de xadrez, em que uma mudança de qualquer uma dessas peças significaria um contexto diferente. Vale ressaltar que o contexto em análise é menos mutável 
que interações face a face, já que se pressupõe interações mediadas pelo computador e circunscritas ao fórum, cuja natureza é fortemente pautada no registro escrito.

Dentro desse conceito, as comunicações empáticas podem ser entendidas como tentativas de alinhar ou realinhar a interação, na busca em gerar uma aproximação ao "sentir" emitido pelo interlocutor, a partir de uma resposta apropriada que se dá àquele que manifestou determinado afeto.

Elocuções como "estou me sentindo decepcionado" ou "o estudo a distância é muito solitário" podem ser entendidas como manifestações de sentimentos sendo vivenciados. Perguntas como "você está sentindo raiva pela falta de suporte?" são construções que permitem explorar e/ou confirmar os sentimentos sendo vivenciados pelo outro. Outros exemplos de frases consideradas empáticas incluem tentativas de solidarizar-se com o outro, como "lamento muito por você" ou "fico feliz em ouvir isso".

Partindo desses elementos, apresentaremos a seguir o caso analisado, bem como, o código construído para a análise das comunicações.

\section{Estudo de CAso}

A plataforma que hospeda a Sala de Aula Virtual da disciplina analisada é o Moodle. A disciplina pertence ao curso de Pedagogia, com carga horária de 60 horas. A base de alunos ativos ao final do semestre era de 281 e a equipe de tutoria é composta por um coordenador e duas tutoras, sendo uma delas também autora do presente artigo. Dois membros da equipe de tutoria possuíam doutorado e o terceiro mestrado. Todas as postagens dos alunos foram respondidas pela equipe, em um prazo entre um e três dias.

O perfil dos alunos é deveras heterogêneo para que consigamos compor um perfil. A disciplina é dada em dezoito polos espalhados por regiões do Estado do Rio de Janeiro, abarcando zona urbana, rural, serrana e interiorana. Há alunos tanto jovens, que procuram o EAD pela facilidade de acesso devido à falta de disponibilidade do ensino público universitário na cidade em que residem, um público que trabalha e que vê na EAD uma melhor opção, os trabalhadores noturnos ou plantonistas, que dificilmente conseguem ajustar a agenda para cursar o ensino presencial, e pessoas com mais de 40 e 50 anos de idade, que buscam melhores condições profissionais e que, majoritariamente, tiveram que trabalhar cedo e não tiveram condições de cursar o Ensino Superior. Há ainda o caso de portadores de diploma que desejam cursar uma segunda graduação, embora esse seja o caso menos expressivo.

Apesar de terem ocorrido quatro fóruns temporários ao longo do semestre, como parte das avaliações, o corpus do artigo, conforme já mencionado, são as mensagens escritas trocadas entre discentes e docentes na Sala de Tutoria. Esse é um fórum permanente do curso, mas acaba funcionando mais como um correio eletrônico, com troca de mensagens assíncronas entre equipe de tutoria e alunos do que propriamente como fórum. Tal informação é importante para compreendermos o contexto a partir do qual se erige o corpus, já que o contexto é "dinâmico e interacionalmente construído" (RIBEIRO \& PEREIRA, 2002), sendo um elemento fundamental para interpretarmos as interações. Em algumas ocasiões, alguns alunos ratificam a dúvida e/ou solicitação do colega, seja de seu polo ou de outro dos dezoito polos localizados em diversas regiões do Rio de Janeiro. 
A metodologia empregada, além de uma revisão bibliográfica acerca da empatia, envolve a coleta e análise das interações entre equipe de tutoria e alunos de uma disciplina ao longo de um semestre letivo, contabilizando ao todo 144 entradas na Sala de Tutoria, sendo que cada uma dessas mensagens deixadas pelos alunos, à medida que vão sendo respondidas, envolvem um desdobramento da interação. Relevante destacar o fato de que a base de alunos era de 281 e só ocorreram 144 conversas na plataforma, o que demonstra uma baixa participação do corpo discente e sinaliza, inclusive, a questão da evasão, realidade presente no EAD do Brasil, com a maior parte dos cursos com uma taxa entre $11 \%$ e $35 \%$, segundo a Associação Brasileira de Educação a Distância, pelo censo de 2016.

Após a coleta, tal material foi categorizado tematicamente, de acordo com os tópicos que pautaram as interações. Os tópicos das conversas entre os interlocutores no semestre, que vai dos meses de julho a dezembro, de 2017, foram categorizados em oito temas: 1) dúvidas e previsão sobre disponibilização de provas ou lançamento de notas, 2) dúvidas sobre a composição das notas e pedidos de revisão de notas, 3) dúvidas sobre conteúdos para as avaliações, 4) dúvidas sobre atividades/provas (problemas técnicos, erro no envio de atividades e confirmação de recebimento de arquivo), 5) pedidos de atividades extras para compor a nota, 6) pedido de disponibilização de gabarito, 7) agradecimentos à equipe, 8) dúvidas sobre conteúdos da disciplina.

Após essa categorização temática, os autores desenvolveram um código para a análise das interações, cuja base é a classificação desenvolvida por Suchman et al. (1997) e a definição de comunicação empática desenvolvida pelos autores da pesquisa. Dessa forma, os excertos serão analisados considerando:

a) a polaridade das emoções/sentimentos, que pode ser positiva, negativa ou neutra;

b) se configura uma comunicação empática ou não, de acordo com a definição desenvolvida pelos autores;

c) se constitui uma oportunidade empática, uma resposta empática ou um terminador empático; e

d) em sendo uma resposta empática, se busca um alinhamento ou um realinhamento da interação.

Os critérios supracitados serviram como uma base para os autores do presente artigo elaborarem uma classificação das elocuções no Fórum de um ambiente de aprendizagem a distância em relação à sua natureza empática:

- Neutra: não contempla demonstrações de emoções.

- Oportunidade Empática Positiva: demonstração de emoção positiva pelo aluno.

- Oportunidade Empática Negativa: demonstração da emoção negativa pelo aluno.

- Resposta Empática: manifestação de emoção positiva por parte do tutor, sem, no entanto, lidar com a emoção expressada pelo aluno.

- Resposta Empática Alinhada: manifestação do entendimento da emoção do aluno e feedback por parte do tutor buscando manter a polaridade dessa emoção.

- Resposta Empática Realinhada: manifestação do entendimento da emoção do aluno e feedback por parte do tutor buscando alterar a polaridade dessa emoção. 
- Terminador Empático: o tutor não oferece um feedback com relação à emoção manifesta e/ou direciona a conversa para longe da emoção demonstrada pelo aluno.

Com base nesses parâmetros, o corpus foi analisado e a classificação foi atribuída pelos três autores do presente trabalho, independentemente. Após a classificação, os pesquisadores realizaram uma análise conjunta das diferenças existentes, construindo uma análise consensual. Sobre essa análise consensual, realizamos a distribuição de frequência das interações em função do tema abordado e do nível de empatia observado. Esse proceder metodológico também foi inspirado no trabalho de Suchman et al. (1997), conforme já detalhamos, ao explicar a referida pesquisa.

Importante destacar que a análise foi realizada sobre a comunicação estabelecida e não acerca da ocorrência ou não da empatia nos agentes da comunicação (tutor ou estudante). Não havia como interpretar a situação vivenciada pelos agentes no momento da comunicação e, mesmo sabendo que outros fatores podem ter influenciado a comunicação, nossa análise teve o intuito de ser objetiva sobre a mensagem escrita. A presente pesquisa também não tem como intenção avaliar a qualidade da tutoria oferecida, mas servir como ferramenta de auxílio a uma tutoria que alcance um maior engajamento e presença dos estudantes na educação a distância.

Quanto aos temas abordados, a base utilizada foi o número de interações iniciadas somadas às interações nas quais houve mudança de assunto durante a troca de mensagens, totalizando 144 interações com diferentes temas.

A análise de frequência dos temas abordados é apresentada no Gráfico 1. O tema mais frequente foi o item 4 (31,3\%), com dúvidas sobre atividades/provas, seguido pelo item 2 $(30,6 \%)$, com dúvidas e pedidos de revisão de provas e pelo item $1(25 \%)$, com dúvidas a respeito das datas de lançamento de notas. Em um nível bem abaixo dos três primeiros critérios, temos os itens $3(6,9 \%)$, com dúvidas sobre conteúdos para as avaliações, $6(2,8 \%)$, com pedidos de disponibilização de gabarito e $5(1,4 \%)$, com pedidos de atividades extras para compor a nota. Uma questão a ser destacada é o baixíssimo nível de dúvidas acerca de conteúdos da disciplina, item 8 , que foi responsável somente por $1,4 \%$ dos temas discutidos nas interações. $\mathrm{O}$ item 7 , agradecimentos à equipe, foi o menor de todos.

Com relação à natureza empática empregado por tutor e discentes em suas comunicações, todas as elocuções foram analisadas e classificadas. Os resultados da análise podem ser vistos no Gráfico 2. Percebemos uma forte presença das interações de conteúdo neutro, isto é, aquelas nas quais não há demonstração clara de emoções, que correspondem a $47,8 \%$ de todas as elocuções. Esse resultado já era esperado, uma vez que as interações entre discente e docentes pressupõem comunicações de caráter informativo, saudações e despedidas. Além disso, o próprio contexto comunicativo (um fórum que funciona como um correio eletrônico permanente, ao longo de toda a disciplina), numa lógica assíncrona, marcada pela forte presença de textos curtos, acaba valorizando um aspecto racional/informativo, o que ajudaria a minimizar a demonstração de emoções, pois, como já abordado, o contexto influencia sobremaneira as interações empreendidas. No caso de um fórum em um AVA, devemos levar em conta as funcionalidades da plataforma, observando também a dinâmica de uso, como a inferência a respeito de operar mais como correio eletrônico. 
Gráfico 1 - Distribuição de Frequência dos Temas Abordados.

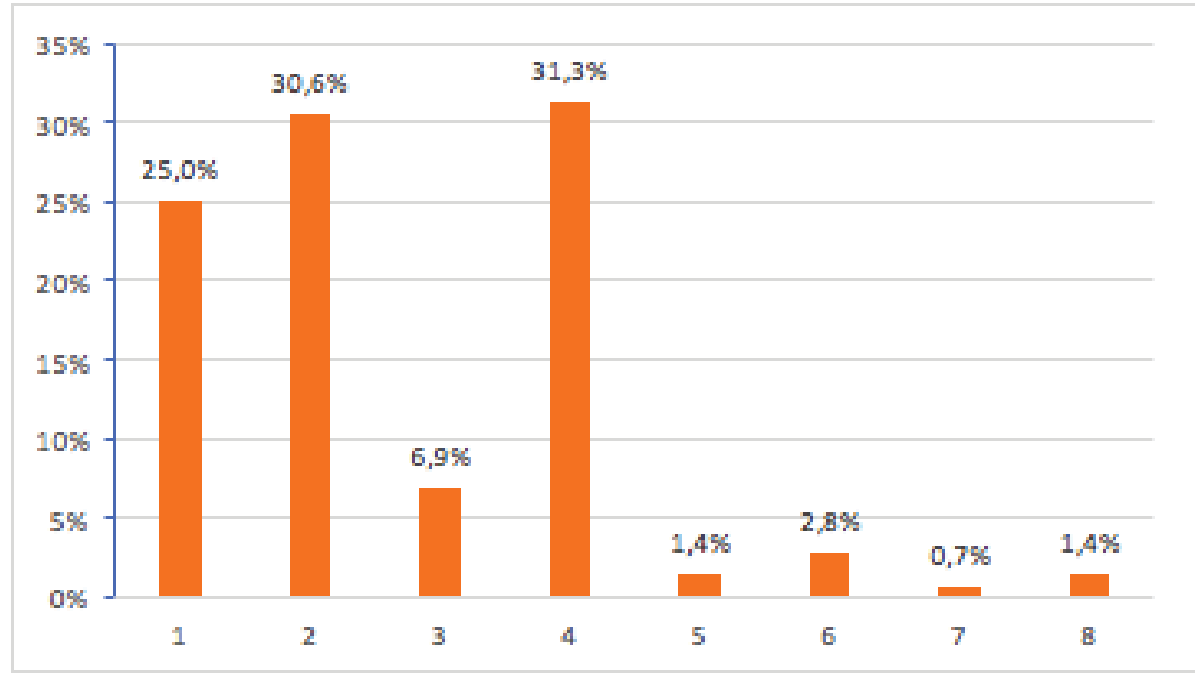

Gráfico 2 - Distribuição de Frequência da Natureza Empática das Comunicações.

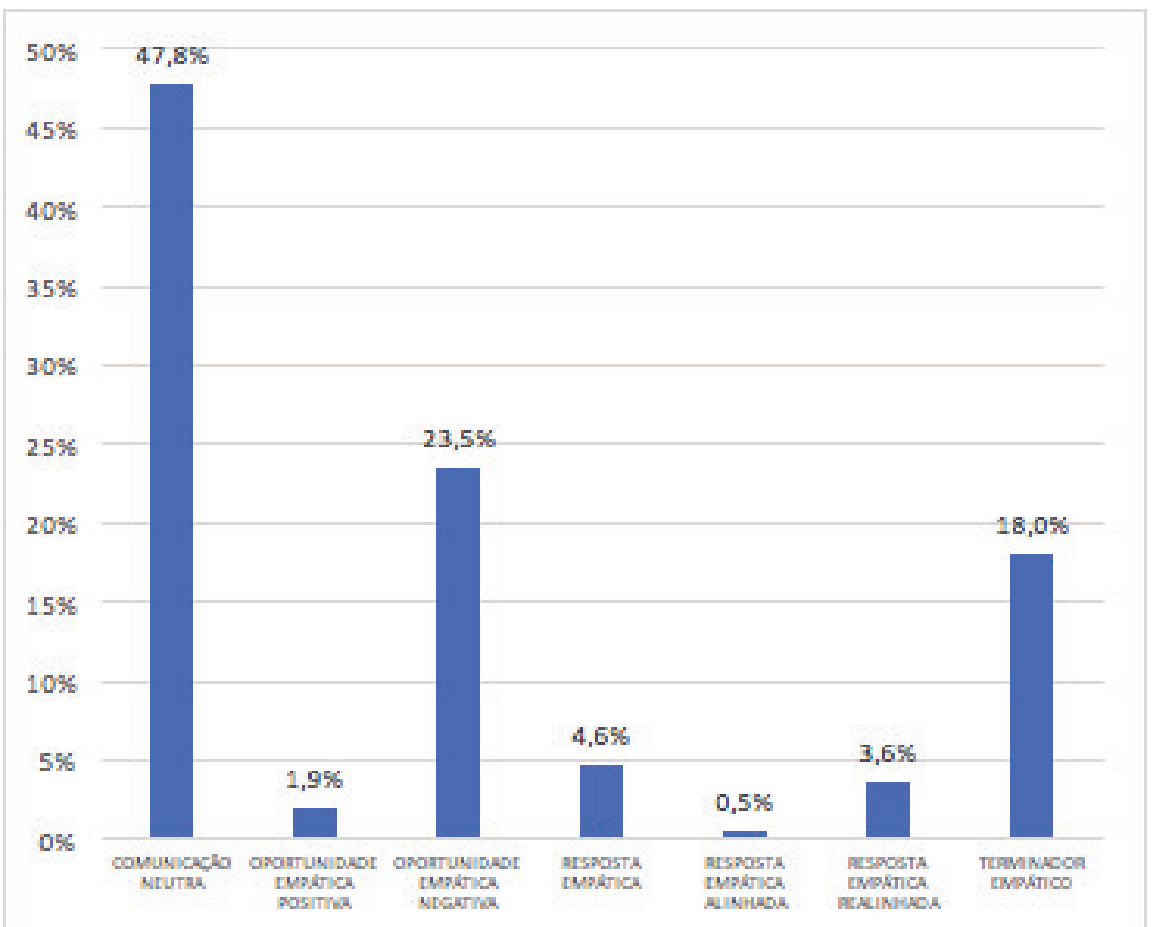

As interações nas quais percebemos algum traço empático correspondem aos demais $52,2 \%$, e podem ser divididas em comunicações dos alunos (93 elocuções) e comunicações dos tutores (98 elocuções).

Das comunicações dos alunos, somente 7,5\% correspondem a oportunidades empáticas positivas, sendo os demais $92,5 \%$ classificados como oportunidades empáticas negati- 
vas. Isso demonstra uma prevalência quase absoluta de emoções de polaridade negativa por parte dos alunos. Vale lembrar que tais emoções negativas estavam quase sempre relacionadas a dúvidas sobre atividades/provas, pedidos de revisão de provas e dúvidas a respeito das datas de lançamento de notas, pois essas três categorias - todas envolvendo avaliações ou notas, englobaram $86.9 \%$ de todas as conversas entre estudantes e tutores, considerando aqui tanto conversas neutras (sem demonstração de emoção), quanto conversas envolvendo emoções negativas ou positivas.

É importante aqui distinguir as comunicações de polaridade negativa do nível de polidez apresentado pelos alunos, posto que é possível ser elogioso, educado e solidário, e, ao mesmo tempo, estar motivado por uma emoção negativa. Um exemplo é exibido a seguir, na Figura 1, elocução 131. Nessa comunicação, a aluna é extremamente gentil e educada, porém demonstra emoções de polaridade negativas, no caso, a ansiedade e o medo.

Figura 1 - Excerto 131. Exemplo de abordagem polida, mas com emoção negativa.

\section{Nota da Ap2}

\section{Boa noite!}

Nao pude fazer a ap1, então decidi tentar as ap2 e ap3, mais nao tenho nenhuma noção de quanto preciso, se saiu a nota da ap2, porque a do polo de São Francisco de Itabapoana não saiu, me ajude por favor. Entendo que vocês lutam pelo o seus direitos, estão mais que certo, merecem respeito mais, Feliz Natal e um próspero ano Novo; Me ajude por favor, minha nota da ap2 năo saiu ainda.mmObrigada!

Fica claro, portanto, que o aluno pode ser gentil, mas apresentar emoções de polaridade negativa. Consideramos pertinente ressaltar esse fato, pois nossa classificação de empatia busca justamente analisar os momentos que os alunos e tutores demonstram determinada emoção (seja positiva ou negativa) e como o interlocutor agiu frente a esse sentimento: ignorando o sentimento manifesto, buscando realinhar esse sentimento, revertendo sua polaridade, ratificando o sentimento, expressando sentimento semelhante, ou mesmo respondendo de forma empática, mas sem dar conta do sentimento manifesto em questão.

Quando analisamos as respostas oferecidas pelos tutores, percebemos que cerca de $67 \%$ são classificadas como terminadores empáticos. Isso significa que houve uma demonstração de emoção por parte do aluno e o tutor não utilizou essa oportunidade para gerar uma comunicação mais afetiva, o que poderia estreitar os laços sociais e criar um clima mais realista de sala de aula. Muitas das respostas dos tutores eram automáticas, com expressões como "vou verificar" ou "vou checar", como a interação 20, apresentada nas Figuras 2 e 3, que consiste em pergunta de aluno e resposta do tutor: 
Figura 2 - Excerto 20A. Exemplo de oportunidade empática negativa.

\section{AD1 Questaio 1.}

Boa tarde.

Estou tentando enviar a questão 1 segundo o tutorial, porém não aparece para mim a opção editar, aparece a opção visualizar depois um espaço e depois comentários. Enfim não está aparecendo a opção editar, segue o print da página. Como devo proceder para efetivar a atividade?

\section{Desde já obrigada !}

Figura 3 - Excerto 20B. Exemplo de terminador empático.

$$
\text { Resposta:AD1 Questso } 1 .
$$

Vou verificar, abraços

Das demais respostas, $17,3 \%$ foram consideradas empáticas, isto é, demonstravam alguma emoção por parte do tutor, mas não lidavam diretamente com a emoção evidenciada pelo aluno naquela comunicação. Como exemplo nas Figuras 4 e 5, nos quais notamos que a aluna está angustiada para saber a nota, a fim de saber se presta ou não a prova final.

Figura 4 - Excerto 134A. Exemplo de oportunidade empática negativa.

\section{Nota da Ap2}

\section{Boa noite!}

Nao pude fazer a ap1, então decidi tentar as ap2 e ap3, mais nao tenho nenhuma noção de quanto preciso, se saiu a nota da ap2, porque a do polo de São Francisco de Itabapoana não saiu, me ajude por favor.Entendo que vocês lutam pelo o seus direitos, estăo mais que certo, merecem respeito mais, Felíz Natal e um próspero ano Novo; Me ajude por favor, minha nota da ap2 não saiu ainda.m?mobrigada!

Figura 5 - Excerto 134B. Exemplo de resposta empática.

\section{Resposta:Nota da Ap2}

AGradecemos dua compreensão, mas não foi a adesão à greve que dificultou a liberação das notas. Outros fatores como chegada de malote e horário de plantão compativel com a chegada dos mesmos e muito pouco tempo para a correçăo foram os fatores que talvez tenham dificultado sua correçăo.

\section{ABraços}

A tutora explica os fatores que dificultaram a correção, mas nada diz sobre a nota da aluna, nem mesmo informa uma previsão de lançamento. Ou seja, a resposta foi empática, mas não levou em conta o sentimento negativo da discente.

Somente $15,3 \%$ das respostas foram percebidas como apropriadas, no sentido de oferecer um retorno às demandas emocionais demonstradas pelos alunos, buscando essas respostas manter uma emoção positiva (resposta empática alinhada) ou alterar uma emoção negativa (resposta empática realinhada).

A interação nas Figuras 6 e 7 demonstra uma aluna preocupada, pois o somatório das questões da prova totalizava apenas 90 , em vez de 100 e a resposta da tutora não só tranqui- 
lizou a aluna, ao afirmar que ninguém seria prejudicado, como valorizou sugestões dadas pela aluna para resolver o problema de pontuação.

Figura 6 - Excerto 90A. Exemplo de oportunidade empática negativa.

\section{Pontuaçajo da prova AP2 do dia 19/12/2007}

\section{Boa Tarde,}

Após o término da prova AP2, notei que a pontuaçăo da prova não contemplava os 10 (dez) pontos que a anterior, ou seja, as questర్es 1,2,3,5 valiam 2 (dois) pontos cada e a questăo 4 somente 1 (um) ponto, totalizando 9 (nove) entāo falta 1 (um) ponto.

Como sugestăo, esse ponto poderia ser distribuido pelas outras questōes ou a questăo 4 também contemplar 2 (dois) pontos.

Aguardo instruçōes a respeito da pontuação exata da prova AP2 para que ninguém saia prejudicado.

Grata pela atenção.

Figura 7 - Excerto 90B. Exemplo de resposta empática realinhada.

\section{Vamos conversar com o coordenador sobre isso, passando inclusive suas sugestőes e, assim que tivermos uma} resposta, nós enviamos um comunicado para todos, ok? Pode ficar tranquila, pois nínguém saírá prejudicado por conta disso.

Abs,

Mas o caso citado representa uma parcela menor das respostas das tutoras que, em várias ocasiões - mais precisamente em $67,3 \%$ - conforme o Gráfico 3, respondiam aos discentes sem levar em consideração o sentimento demonstrado, numa abordagem mais pragmática, no sentido de encerrar o diálogo, resolvendo a dúvida. A distribuição de frequência da natureza empática utilizada pelos tutores em suas respostas é apresentada no Gráfico 3.

Gráfico 3 - Distribuição de Frequência da Natureza Empática das Respostas Oferecidas pelos Tutores.

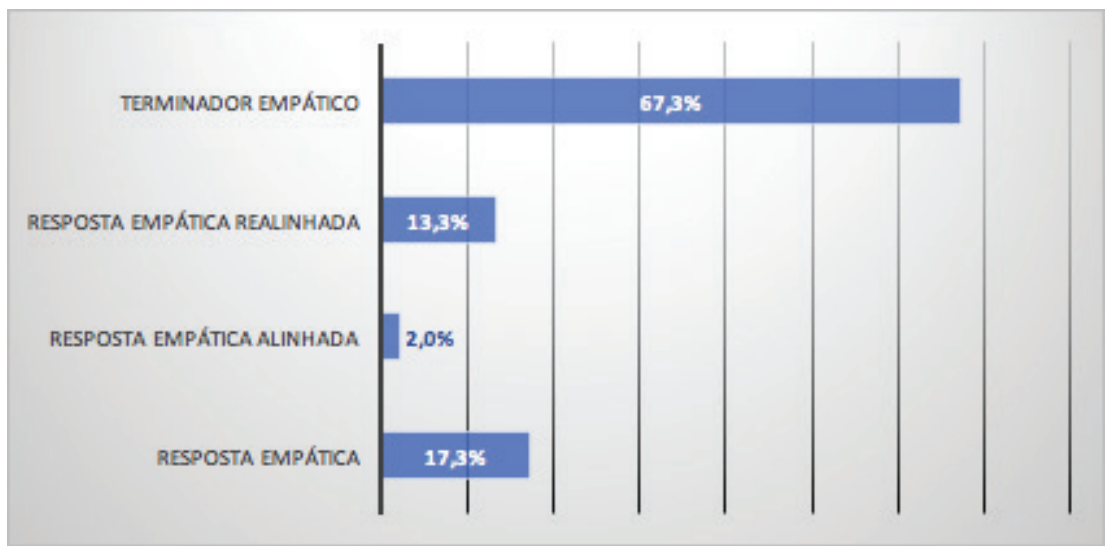


Cabe aqui ressaltar que a própria nomenclatura da Sala de Tutoria, que divide as dúvidas em "pendentes" e "resolvidas", pode ajudar a estimular essa atitude nos tutores. No excerto 40, Figuras 8 e 9, a aluna confessa a inexperiência no mundo digital, e se mostra aflita com a nota.

Figura 8 - Excerto 40A. Exemplo de oportunidade empática negativa.

\section{Nota ad1/resposta mensagem}

Prezada tutora,

Coloquei esta mensaggem no dia 0ev09, Gostaria que revisse a minha nota de ad1, pois apesar da pouca inexperiência no mundo digital, me esforcel para cumprir todas as questoes que foram colocades. Por que ful tilo mal pontuada, pode me explicar? Gostaria de melhorar, pode me ajudar? estou aguardando resposta, mas resolvi colocar tambelm aqui na sala de tutoria.

Desde já agradeco,

Figura 9 - Excerto 40B. Exemplo de terminador empático.

\section{Resposta:Nota ad1/resposta mensagem}

OLá Sueli sua nota foi retificada no SISTACAD, não havia sido lançadas as duas primeiras atividades. ABraços

Apesar de ter alterado a nota, que havia sido computada erroneamente, o fato de a aluna ter se esforçado não foi valorizado pela tutora, que tampouco abordou a questão da inexperiência digital, buscando não só incentivar a aluna, mas também converter a emoção negativa em positiva. Esse dado ajuda a explicar que não só os alunos se preocupam demasiadamente com questões inerentes à nota, como os próprios tutores também se portam dessa maneira, ao simplesmente enfatizar a questão da alteração de grau.

De todo corpus analisado, a fala da Figura 10 foi uma das que mais explicitamente demonstraram emoções negativas, não tendo o tutor, na Figura 11, lidado com a emoção em voga.

Figura 10 - Excerto 48A. Exemplo de oportunidade empática negativa.

\section{Nota da Ad1}

Não estou satisfeita com a minha nota, me dediquei muito e recebi uma nota muito baixa, não entendi nada. Participei do forum comentei a postagem do colega ,enviei as fotos de família,enfim realizei a Ad e a nota foi um fracasso, que decepçăo. Fiquei desmotivada.

Figura 11 - Excerto 48B. Exemplo de terminador empático.

\section{Resposta:Nota da Ad1}

A sua nota sobre a at9ividade da Wik não havia sido computada. Jà acertamos. abraços 
A resposta da tutora, no entanto, foi pragmática, apenas informando que um dos exercícios que integravam a avaliação não havia sido computado, estimulando no corpo discente um sentimento de que tudo se resume à nota e avaliações, não coincidentemente os temas que envolviam nota e provas abarcavam $86,9 \%$ de todas as conversas entre estudantes e tutores.

\section{CONSIDERaÇões finais}

Durante a presente pesquisa, realizamos a análise das interações que ocorreram ao longo de um semestre na Sala de Tutoria, espaço que funciona como fórum eletrônico de uma Disciplina EAD, no curso de Pedagogia de uma universidade federal brasileira. Classificamos o corpus da pesquisa quanto ao tema abordado nas interações e quanto ao nível de comunicação empática adotado por alunos e tutores. A comunicação empática, conforme visto em Vedove \& Camargo (2008), é elemento fundamental no desenvolvimento da empatia por parte do tutor e por possibilitar a construção de um ambiente acolhedor por meio da modulação da linguagem utilizada, permitindo o engajamento dos alunos em um ambiente de ensino-aprendizagem que gera uma comunidade efetiva de aprendizagem, fator que constitui um dos maiores obstáculos ao e-learning.

Quanto aos temas abordados nas interações, sobressaem aqueles relacionados às dúvidas com as provas $(31,3 \%)$, pedidos de revisão de provas $(30,6 \%)$ e dúvidas sobre datas de lançamento de notas (25\%). Assim, fica claro o baixo caráter dialógico do Fórum, que serve mais como uma forma de cobrança da nota, que parece constituir a maior preocupação dos alunos. Também transparece a falta de construção de uma comunidade de conhecimento, ancorada na troca de informações e perspectivas entre alunos e tutores, quando vemos que somente $1,4 \%$ das interações tiveram como tema a discussão de dúvidas acerca do conteúdo das disciplinas.

Acreditamos que um dos fatores que ajudam a dar forma a esse contexto é o baixo nível de comunicação empática nas interações. Das 144 interações analisadas, 25,4\% possuíam manifestações emocionais por parte dos alunos. Porém, somente $8,7 \%$ de todas as interações demonstravam algum grau de empatia por parte dos tutores. Considerando as oportunidades empáticas oferecidas pelos alunos, somente $32,7 \%$ tiveram uma contrapartida na comunicação dos tutores, sendo que apenas $15,3 \%$ tinham um direcionamento no sentido de lidar efetivamente com a emoção demonstrada pelos alunos.

Os dados apresentados demonstram falta de preparo por parte dos tutores quanto ao processo de comunicação empática, uma das competências psicológicas exibidas por Bernardino (2011), e sua importância na construção de um ambiente propício à aprendizagem. Esse panorama corrobora os estudos que apontam para a falta de um senso de presença (KEHRWALD, 2008) existente nas interações do e-learning e, por conseguinte, para a dificuldade na construção de um clima de sala de aula, engajamento e retenção dos alunos, principalmente em cursos de maior duração. Obviamente, as condições de trabalho impactam essa atividade, já que apenas dois tutores precisam gerenciar uma sala de tutoria com quase 300 alunos, de 18 polos distintos. Somado a esse panorama, a maioria dos tutores possui outros vínculos empregatícios, a fim de complementar a renda. 
Uma sugestão para que esse panorama seja mudado seria o desenvolvimento de treinamentos sobre empatia e comunicação empática para os tutores e mesmo para os alunos, uma vez que não só a aprendizagem, mas a atuação profissional pode ser alavancada por meio dessa competência. Outra sugestão seria a construção de plataformas de comunicação on-line que privilegiem a transferência do aspecto emocional, destacando elementos como os emoticons ou com o aparecimento de breves sugestões, em formato estilo pop up, que forneçam dicas para tutores e alunos se comunicarem de forma empática, ajudando nesse momento da escrita.

Finalizando, a presente pesquisa limitou-se à análise de uma turma específica e a validade dos seus resultados deve ser verificada por outras pesquisas que expandam esse corpus. Outra restrição deste trabalho se refere aos aspectos culturais existentes nas comunicações em diferentes países e mesmo em diferentes regiões de um mesmo país. Dessa forma, os resultados obtidos devem ser analisados sob a luz das características específicas dessas regiões.

\section{REFERÊNCIAS}

BERNARDINO, H. S. A tutoria na EaD: os papéis, as competências e a relevância do tutor. Revista Paidéi@-Revista Científica de Educação a Distância, v. 2, n. 4, 2011.

BLUMER, H. A sociedade como interação simbólica. In: Coelho, M. (Org. e trad.). Estudos sobre Interação: textos escolhidos. Rio de Janeiro: EdUERJ, 2014, p. 75-90.

DAVIS, M. H. A multidimensional approach to individual differences in empathy. Journal of Personality and Social Psychology, v. 10, n. 85, 1980.

DAVIS, M. H. Empathy: A Social Psychological Approach. Colorado: Boulder, 1996.

EISENBERG, N., \& FABES, R. A. Empathy: Conceptualization, measurement, and relation to prosocial behavior. Motivation and Emotion, v. 14, n. 2, p. 131-149, 1990.

FERNÁNDEZ-PINTO, I., LÓPEZ-PÉREZ, B., \& MÁRQUEZ, M. Empatía: Medidas, teorías y aplicaciones en revisión. Anales de psicología, v. 24, n. 2, 2008.

FREIRE, P. Pedagogia do oprimido, 9. ed. Rio de Janeiro: Paz \& Terra, 1981.

GOFFMAN, E. FOOTING. In: RIBEIRO, B. T., GARCEZ, P. M. (Org.). Sociolinguística Interacional. São Paulo: Loyola, 2002, p. 107-148.

KEHRWALD, B. Understanding social presence in text-based online learning environments. Distance Education, v. 29, n. 1, p. 89-106, 2008. 
MACHADO, L. D.; MACHADO, E. C. O papel da tutoria em ambientes de EAD. In: Congresso Internacional de Educação a Distância, 2004, p. 1-11. Disponível em: $<$ http://www. abed.org.br/congresso2004/por/pdf/022-TC-A2.pdf>. Acesso: 26 mai. 2019, 14:56:30.

MCLUHAN, M. A galáxia de Gutenberg; a formação do homem tipográfico. São Paulo: Nacional, 1977.

MCLUHAN, M. H. Os Meios de Comunicação como extensões do homem: understanding media. São Paulo: Cultriz, 1996.

PAIVA, J., FIGUEIRA, C., BRÁS, C., \& SÁ, R. E-learning: O estado da arte. Revista Sociedade Portuguesa de Física. Softciências, 2004. Disponível em: < http://nautilus.fis. uc.pt/el/Livro eL.pdf $>$ Acesso em 24 abr. 2019, 09:04:35.

PLATT, F. W., \& KELLER, V. F. Empathic communication. Journal of General Internal Medicine, v. 9, n. 4, p. 222-226, 1994.

PREECE, J., \& GHOZATI, K. Experiencing empathy online. In: RICE, R; KATZ, J. The Internet and health communication: Experiences and expectations, 2001, p. 147-166.

RIBEIRO, B. T., \& PEREIRA, M. D. G. D. A noção de contexto na análise do discurso. Veredas Est. Ling Juiz de Fora, v. 6, n. 2, 49-67, 2002.

ROGERS, C. R. The necessary and sufficient conditions of therapeutic personality change. Journal of consulting psychology, v. 21, n. 2, 1957.

SALGADO, M. M. Del valor estético de la empatía al negocio inteligente de las emociones: La psicología estética de Theodor Lipps a las puertas del tercer milenio. Revista de Historia de la Psicologia, v. 21, n. 2, p. 359-372, 2000.

SUCHMAN, A. L., MARKAKIS, K., BECKMAN, H. B., \& FRANKEL, R. A model of empathic communication in the medical interview. Jama, v. 277, n. 8, p. 678-682, 1997.

TOFLER, A. A Terceira Onda, 25. ed. Rio de Janeiro: Record, 1980.

VEDOVE, J. C. D., \& CAMARGO, R. T. M. D. A influência da empatia na relação tutor-aluno. Revista Intersaberes, v. 3, n. 6, p. 155-165, 2008.

WALSHAW, M., \& DUNCAN, W. Hermeneutics as a methodological resource for understanding empathy in on-line learning environments. International Journal of Research \& Method in Education, v. 38, n. 3, p. 304-319, 2015. 


\section{DAdos dos AUTORES}

\section{Julio Cesar Teixeira de Freitas}

Mestre em Educação e Tecnologias Digitais pela Universidade de Lisboa. Professor do Colégio Pedro II, do curso técnico de Administração, Rio de Janeiro/RJ-Brasil. juliofreit@, gmail.com

\section{Tamara de Souza Campos}

Doutora em Memória Social (Memória e Linguagem) pela Universidade Federal do Estado do Rio de Janeiro/RJ-Brasil. Professora de Comunicação Social da Universidade Estácio de Sá, Petrópolis/ RJ-Brasil. tamara.campos86@gmail.com

\section{Elisa Maria dos Anjos}

Doutora em Memória Social (Memória e Espaço) pela Universidade Federal do Estado do Rio de Janeiro/RJ-Brasil. Professora de Ciências Sociais da Universidade Federal do Maranhão/MA-Brasil elisadosanjos@gmail.com

Submetido em: 20-1-2019

Aceito em: 7-5-2019 